\title{
Projeto Pedagógico do Curso de Licenciatura em Inglês da UFAL: os letramentos em questão
}

\section{Pedagogical Project of the Licentiate Course in English at UFAL: literacies in question}

Paulo Rogério Stella*

Universidade Federal de Alagoas (UFAL)

Maceió - Alagoas/Brasil

Roseanne Rocha Tavares**

Universidade Federal de Alagoas (UFAL)

Maceió - Alagoas/Brasil

RESUMO: Este artigo visa à análise e à discussão do Projeto Pedagógico de Licenciatura em Inglês da Universidade Federal de Alagoas - Maceió no que se refere aos sentidos de letramentos. Considerando que o documento escrito reflete uma posição socioideológica (CHARTIER, 1999); que um projeto deve ter não somente a função pedagógica, mas também política no sentido de modificação da realidade (FREIRE, 2001); e que a evolução desse documento depende de revisōes críticas (PENNYCOOK, 2001), observamos que o projeto, publicado em 2007, revela um posicionamento muito restrito no que se refere ao conceito de texto e às modalidades concorrentes na produção de sentido (MONTE-MÓR, 2011) desses textos. $\mathrm{O}$ conceito de letramento (no singular) se restringe à leitura e à escrita somente e está aparentemente dissociado do uso de tecnologias.

PALAVRAS-CHAVE: projeto pedagógico, letras, letramentos, tecnologias, produção de sentido.

ABSTRACT: This article aims at analyzing and discussing the Pedagogical Project of the Licentiate Course in English at the Federal University of Alagoas - Maceió in relation to the meanings of literacies. Considering that a written document reflects a socio-ideological position (CHARTIER, 1999); that a project should not only function pedagogically, but also politically in the sense that it should provoke a change in the reality (FREIRE, 2001); and that the evolution of such a document depends on critical revisions (PENNYCOOK, 2001), we observed

\footnotetext{
* prstella@uol.com.br

** tavaresroseanne@gmail.com
} 
that this project, published in 2007, reveals a considerably restricted position in relation to the concurrent modalities and in relation to the modalities concurrent in the process of meaning-making (MONTE-MÓR, 2001) of these texts. The concept of literacy (in the singular) is restricted only to reading and writing and is apparently dissociated from the use of technologies.

KEYWORDS: pedagogical project, letters, literacies, technologies, meaningmaking.

\section{Introdução}

Este texto apresenta uma discussão sobre os sentidos de letramentos no Projeto Político-Pedagógico ${ }^{1}$ do curso de Letras - Licenciatura em Inglês da Universidade Federal de Alagoas, posto em funcionamento em 2007. De acordo com Roger Chartier (1999), a importância do estudo sobre os documentos escritos está na possibilidade da observação das relações entre homem e sociedade, pois, funcionando dentro do contexto em que foi produzido, o documento escrito fixa, preserva e transmite saberes constituídos em um determinado tempo e espaço, refletindo pontos de vistas sobre esse momento histórico.

Em decorrência disso, entendemos que um projeto político-pedagógico de curso é o documento que reflete o posicionamento do grupo no momento de sua produção, funcionando como centro organizador das ações docentes. Por isso, o projeto contém os valores desse grupo, historicamente marcados pelo instante de produção, que norteiam as ações do próprio grupo no período posterior à publicação. Além disso, os resultados esperados em relação aos alunos egressos refletem esse posicionamento fixado no documento escrito. Lembramos, também, seguindo as palavras de Paulo Freire (2001), que um projeto, além de pedagógico, é também político, pois deve sempre interferir na realidade no sentido de mudá-la para melhor; isto é, não é possível pensar a história e as relações humanas no seu aspecto processual e dialético "sem projeto de natureza político-pedagógica no sentido da transformação ou da reinvenção do mundo" (FREIRE 2001, p. 18).

Desse modo, é nossa firme convicção que um documento dessa natureza deva ser constantemente rediscutido em seu posicionamento com o objetivo de adequá-lo às mudanças sociais que pressionam os sentidos constituídos no texto, promovendo a reformulação dos princípios e garantindo a evolução do

${ }^{1}$ Doravante, PPP. 
material pela adequação aos novos sentidos produzidos. Segundo Mikhail Bakhtin e Valentin Volochinov (2010), as palavras lentamente acumulam modificações ocorridas pelo uso até o instante em que essas modificações passam a integrar o sentido dessas mesmas palavras, garantindo sua existência pela renovação de sentidos.

Por esse motivo, consideramos a necessidade constante de revisão do PPP na esteira do que Alaister Pennycook (2001) denomina linguística aplicada crítica. Queremos dizer com isso que pretendemos uma discussão posicionada política e eticamente sobre as questôes relativas às práticas de linguagem, problematizando e interferindo nessas práticas com o objetivo de modificá-las. Consideramos, ainda, que um trabalho crítico com a linguagem somente pode ser efetivo se possibilitar a autocrítica, no sentido da avaliação dos procedimentos e práticas utilizadas pelo grupo em questão. Por esse motivo, justifica-se a discussão que ora se estabelece para o PPP, extrapolando as páginas deste artigo para atingir efetivamente resultados com a possível revisão dos conceitos apresentados no projeto. Nas palavras de Pennycook (2001, p. 5, tradução nossa), "a linguística aplicada crítica vai além da mera relação entre contextos linguísticos e contextos sociais, mas parte de um ponto de vista que enxerga as relações sociais como problemáticas". ${ }^{2}$ Por isso, o trabalho com a linguagem não pode ser neutro, mas deve prever uma tomada de posição política, entendida como uma ação ética e uma atuação consciente em relação à realidade estabelecida. Esta discussão, por conseguinte, busca o envolvimento dos participantes "num projeto moral e político que possibilite a realização de mudanças" (PENNYCOOK 1998, p. 25, tradução nossa).

Por fim, consideramos que o ensino de língua inglesa ${ }^{3}$ deve focalizar as práticas de letramentos como práticas de produção de sentido envolvendo os meios de produção, circulação e recepção de informações em seus vários suportes. Isso implica uma visão de língua clara e um viés pedagógico diferenciado para os processos relacionados aos letramentos. Segundo Joe Lo Bianco (2000, p. 89, tradução nossa), letramentos envolvem a "habilidade de entender códigos complexos de linguagem e de letramentos sempre crescentes; a habilidade em usar os múltiplos modos em que aqueles códigos são

\footnotetext{
2 " [...] critical applied linguistics is concerned not merely with relating language contexts to social contexts but rather does so from a point of view that views social relations as problematic".
}

${ }^{3}$ Doravante, LI. 
transmitidos e colocados em funcionamento; e a capacidade de entender e gerar sentidos cada vez mais ricos e elaborados". ${ }^{4}$

Isso posto, dividimos o presente artigo em quatro seções, além desta introdução: na primeira seção, intitulada "O PPP e os letramentos", trataremos de conceituar língua e texto em relação ao sentido de letramentos que pretendemos para um PPP que se proponha a estabelecer os valores para a formação de professores de inglês atuantes na escola básica e regular. Em seguida, na seção intitulada "O letramento como aquisição/aprendizagem de leitura e de escrita", trataremos do sentido de letramento como se apresenta no PPP, ou seja, no singular e relacionado à escrita e à leitura. Posteriormente, na seção intitulada "A questão da tecnologia", trataremos da discussão sobre a relação entre letramentos e tecnologias, observando o tratamento que o PPP dá a essa questão. Por fim, já nas "Considerações finais", retomaremos os pontos discutidos, levantando questões relacionadas às possíveis revisões desse projeto.

\section{O PPP e os letramentos}

Ao discutirem a formação de professores de inglês, Elaine Tarone e Dick Allwright (2005) chamam a atenção para a necessidade não somente do tratamento das questóes pedagógicas, mas também para o ensino linguístico. Argumentam que a atividade de ensino de línguas estrangeiras tem especificidades que a diferenciam de outras atividades docentes: o professor de língua estrangeira tem não apenas que focalizar sua atenção para o conteúdo do que está sendo dito, mas também para a forma do enunciado. Nas palavras dos autores, os professores têm o papel de "aprender a prestar atenção às formas da língua produzidas pelos alunos enquanto simultaneamente processam o conteúdo dos enunciados, algo que não é requerido de um professor de biologia ou de balé"5 (TARONE; ALLWRIGHT 2005, p. 7, tradução nossa).

O valor de verdade do enunciado dos autores ganha uma dimensão mais complexa no deslocamento do foco de trabalho para a realidade da formação

\footnotetext{
4 "[...] the ability to understand increasingly complex language and literacy codes; the ability to use the multiple modes in which those codes are transmitted and put to use; and the capacity to understand and generate the richer and more elaborate meanings they convey".

5 " $[\ldots]$ learning to pay attention to the linguistic forms produced by our students while simultaneously processing the content of their utterances is something that is not required of a biology teacher or a ballet teacher".
} 
de docentes em LI para a escola básica, regular e pública em Alagoas. Isso porque tratamos não somente com as questôes relativas à pedagogia de ensino de língua estrangeira, mas também lidamos com a necessidade do ensino da língua aos graduandos que, em sua maioria, não a falam. Isso significa que o PPP tem o desafio de orientar o funcionamento político e pedagógico do curso em duas direçóes: deve responder às demandas de ensino e aprendizagem de LI direcionadas para as questôes pedagógicas, didáticas e linguísticodiscursivas, bem como guiar as questôes relacionadas à proficiência linguística em LI para os futuros docentes.

A complexidade da situação requer um ponto de vista que englobe, além do conceito de letramentos, conceitos relacionados à língua em uso; reflexões sobre valores locais em relação aos globais, ou vice-versa; e um ponto de vista sobre texto que seja amplo o suficiente para dar conta da evolução tecnológica, entre outros fatores, compondo um conjunto de noçōes norteadoras do projeto como um todo. Nesse sentido, afirmamos, seguindo Bakhtin e Volochinov (2010), que o conceito de língua deve incorporar as instâncias de produção e recepção desses textos, materializados por um locutor e um interlocutor (falante e ouvinte) em constante diálogo. Dado que estão posicionados em suas culturas, por onde circulam valores éticos, históricos, sociais e ideológicos, as enunciaçôes produzidas por esses dois participantes são orientadas e se orientam em várias direções em relação a esses valores circulantes que são transmitidos, interpretados e reinterpretados pelos sujeitos. Ao se comunicarem por meio da língua, comunicam não somente um ponto de vista sobre eles mesmos, sobre seu espaço e seu tempo, mas também oferecem um ponto de vista valorado sobre o outro, com quem se comunicam.

Com efeito, a palavra é a arena onde se confrontam os valores sociais contraditórios; os conflitos da língua refletem os conflitos de classe no interior mesmo do sistema: comunidade semiótica e classe social não se recobrem. A comunicação verbal, inseparável das outras formas de comunicação, implica conflitos, relações de dominação e de resistência, adaptação ou resistência à hierarquia, utilização da língua pela classe dominante para reforçar seu poder etc. (BAKHTIN; VOLOCHINOV, 2010, p. 15).

O diálogo se torna o único meio existente de interação e de consequente construção de conhecimento, entendido, segundo Marilia Amorim (2003), como uma tensa relação de confronto de pontos de vistas, de diferentes contextos. Nesse processo, o sentido - o conhecimento - estabelece-se, ou seja, 
somente quando há confronto de valores, experiências, histórias, ideologias é que o sentido é produzido. A esse respeito Bakhtin e Volochinov (2010) nos informam que

A significação não está na palavra nem na alma do falante, assim como também não está na alma do interlocutor. Ela é o efeito da interação do locutor e do receptor produzido através do material de um determinado complexo sonoro. E como uma faísca elétrica que só se produz quando há contato dos dois polos opostos (BAKHTIN; VOLOCHINOV, 2010 , p. 135, grifos dos autores).

Dessa perspectiva, a produção de sentido implica a percepção dos participantes do diálogo de suas posiçóes diferenciadas, ou seja, implica, segundo Tzvetan Todorov (2003), a percepção de que ambos não são o mesmo, mas outros, às vezes, radicalmente outros, o que constrói, reforça as alteridades e preserva as identidades. Podemos dizer que a interação entre os participantes do diálogo é uma relação complexa que envolve conhecimento, reflexão e crítica sobre as posições desses participantes. A língua, nesse processo, é a atividade privilegiada para a reflexão, já que é constitutiva das relações.

O diálogo, entendido como um processo mais amplo do que simplesmente a relação direta entre falante e ouvinte, é composto por qualquer produção situada e materializada em texto em suas várias modalidades. Bakhtin (2003) define texto como o único objeto concreto de acesso ao outro e disponível para o estudo das interações, o que quer dizer que permite a observação e a reflexão sobre os valores e posicionamentos dos participantes, constituindo-se no artefato concreto de uma cultura.

Segundo The New London Group (2000), o conceito de texto deve dar conta de todas as possíveis manifestaçôes interativas relacionadas às infinitas possibilidades de construção e produção de sentidos. Essas possibilidades aumentam consideravelmente quando se incluem as tecnologias de comunicação digital, em que o textual se constitui não somente do próprio texto escrito ou oral, mas também a partir da interrelação com a imagem e o som, o áudio e o desenho, entre outros. O grupo chama esse processo de modos de produção de sentidos, ${ }^{6}$ uma vez que entende que o sentido é produzido em várias direções e pelos vários participantes da comunicação. Desse modo, compreende-se que o sentido não é estático, mas produzido não somente em decorrência do

${ }^{6}$ Do original: "modes of meaning-making". 
suporte de circulação desses textos, mas também pelo locutor desse texto, assim como pelo seu interlocutor. Isso resulta na dinâmica da constante e infinita negociação das diferenças, das alteridades, advindas não apenas da contínua percepção sobre as diversidades locais, mas também relativas às possibilidades estabelecidas pela conectividade global, em relação tanto à vida pessoal quanto à vida profissional.

Do ponto de vista local, o uso da língua estrangeira, em nosso caso particular, de LI, permite a construção de alteridades locais mais firmes pela possibilidade da reflexão e comparação entre valores oriundos de outras culturas e valores circulantes localmente, preservando-os enquanto identidade de um grupo. A preservação das identidades por meio do fortalecimento das alteridades possibilita, do ponto de vista global, a tolerância na relação entre os indivíduos pelo entendimento das distinçōes entre valores, o que facilita a promoção da inserção dos indivíduos nos meios de produção e de circulação de informações e de conhecimento.

Ao tratar da relação entre povos, Edgar Morin (2000), entende que a discussão sobre as relaçôes entre o global e o local deva se estender historicamente ao período da formação da modernidade. Como herança das conquistas estabelecidas no início da era moderna e dos processos coloniais estabelecidos a partir do século XIX, o autor afirma que, em se tratando das naçôes europeias, parece haver um pré-construído de que são naçōes soberanas, desenvolvidas cientificamente, portanto detentoras do saber e cujo conhecimento deva ser transmitido. Em oposição a isso, parece também haver outro pré-construído para as outras naçôes cuja sabedoria local, às vezes de cunho mitológico, não é passível de crédito, portanto deve ser descartada ou substituída pela outra. Nas palavras do autor,

a ideia do mundo europeu e mais largamente ocidental era de que toda a razão, sabedoria, verdade estavam concentradas na civilização ocidental. As outras nações e civilizações eram atrasadas e infantis, nelas não havia sabedoria real, mas unicamente mitologia e, ainda, valorada como superstição (MORIN 2000, p. 27).

O autor afirma que a construção do conhecimento, denominado integral, somente pode existir se global e local, ou o considerado centro e as possíveis margens, interagirem de forma a construírem sentido para ambas as partes. Nas palavras do autor, "o conhecimento do todo necessita também do conhecimento das partes, isto é fundamental e também muito difícil" (MORIN 2000, p. 34). 
Parece-nos, então, que um PPP deva ter o firme propósito de promover o diálogo entre as várias instâncias de produção de conhecimento, permitindo a construção de sentidos advindos do confronto de valores e preservando as identidades locais com a construção de alteridades firmes, além de levar em consideração os usos das novas tecnologias como mediadoras dos processos de interação, possibilitando o contato entre culturas fisicamente distantes.

Desse ponto de vista, o PPP deve conter uma noção de letramentos que leve em consideração não somente o conceito de língua sobre o qual o projeto deve pautar suas ações formativas, mas também a relação entre a circulação de valores no contexto local e global, além da noção de texto em suas várias modalidades. Por esse motivo, alinhamo-nos a Colin Lankshear e Michele Knobel (2011), que consideram os letramentos "maneiras socialmente reconhecidas nas quais as pessoas geram, comunicam e negociam sentidos, como membros de discursos, por meio de textos codificados"7 (LANKSHEAR; KNOBEL 2011, p. 32, tradução nossa).

Com esses princípios em mente, passaremos, a seguir, à análise do PPP propriamente dito.

\section{O letramento como aquisição/aprendizagem de leitura e de escrita}

O PPP inicia com uma parte introdutória, que discute a importância da articulação entre a teoria e a prática na formação do professor da área de Letras, afirmando que o projeto se justifica como proposta integradora entre teoria e prática. Em seguida, apresenta algumas características esperadas no perfil do egresso, incluindo a capacidade de investigação aliada à ação eà ética, o que desemboca nas competências e habilidades pretendidas no processo formativo. O PPP prossegue apresentando a grade curricular, que se divide em disciplinas do núcleo básico e comum do curso, incluindo Linguística, Língua Portuguesa, Latim, etc., e disciplinas do núcleo de formação, distintas por dois grupos: o primeiro apresenta as disciplinas referentes à língua e literatura inglesas, e o segundo apresenta aquelas de formação docente, incluindo as de licenciatura. Os três últimos capítulos do PPP apresentam o ordenamento curricular com as ementas referentes a cada uma das disciplinas do curso e suas respectivas bibliografias. Na sequência, o PPP apresenta as diretrizes para o estágio supervisionado, trazendo aspectos da legislação. Por fim, o projeto apresenta

\footnotetext{
7 " [...] socially recognized ways in which people generate, communicate, and negotiate meaning, as members of discourses, through the medium of encoded texts".
} 
a proposta de atividades acadêmico-científicas, objetivando a complementação da formação linguística, pedagógica e cultural dos alunos de inglês.

A introdução do PPP discute os avanços e os recuos nos programas de alfabetização com foco na formação de docentes para o ensino básico, o que remete o texto explicitamente ao termo letramento, no singular, que parece estar em uma relação hierárquica com alfabetização. Parece-nos, assim, que a alfabetização é um estágio anterior ao letramento, que, por sua vez, parece incorporar um sentido mais englobante. Segundo o PPP (2007 p. 6), apesar dos esforços para a promoção do "fim do analfabetismo, a alfabetização da totalidade de jovens e adultos ainda não está assegurada”. No trecho seguinte, aparece pela primeira vez o termo letramento, na discussão sobre a dificuldade em aplicá-lo: lemos; difícil é o alcance de "um nível satisfatório de letramento". O termo cidadania aparece juntamente com alfabetização e letramento, estabelecendo uma relação de causa e consequência com o trecho anterior. Assim, as dificuldades enfrentadas pelos programas de alfabetização que impossibilitam um nível satisfatório de letramento impedem que os "egressos desses programas [consigam] o pleno exercício da cidadania” (PROJETO, 2007, p. 6).

O sentido de letramento, aproximado de alfabetização e ligado à escrita e à leitura, apresentado no PPP, parece fazer referência a Freire (2001). O autor entende alfabetização como a possibilidade do exercício da cidadania, o que "tem que ver com a condição de cidadão, quer dizer, com o uso dos direitos e o direito de ter deveres de cidadão" (FREIRE 2001, p. 25). A alfabetização como ação política no sentido da intervenção do educador se torna o meio pelo qual o educando acede a esses direitos e deveres. E isso se dá pelo aproveitamento da experiência dos educandos na construção do conhecimento, obedecendo à sequência: "pensamento, linguagem, concretude, apreensão do concreto, abstração, conhecimento" (FREIRE 2001, p. 29). Nesse sentido, o educador, o alfabetizador, é aquele que estabelece uma relação dialética entre teoria e prática, ou seja, entre o rigor da ciência e sua adequação à situação histórica dos envolvidos no processo. Em outras palavras,

reconhecer que, se o papel organizador, interferente, do educador progressista não é jamais o de alojar-se, de armas de bagagens, na cotidianidade popular, não é também o de quem, com desprezo inegável, considera nada ter a fazer com o que lá ocorre (FREIRE 2001, p. 27).

A perspectiva de Freire (2001) focaliza as possibilidades abertas pela leitura e pela escrita como entendimento do posicionamento do cidadão em 
relação às estruturas de dominação. Entretanto, em alguns momentos, o PPP parece estabelecer certa dicotomia entre essas duas atividades. Nos parágrafos seguintes da introdução, o texto aproxima a aquisição de escrita ao campo de estudos da linguagem, "os estudos sobre a aquisição da escrita também têm tido um lugar de destaque nas pesquisas da área" (PROJETO, 2007, p. 9). E aproxima a perspectiva de aquisição de leitura e formação de leitores ao campo dos estudos de literatura, "situação que faz voltar o olhar, afirmativamente, para a comunidade de leitores, cuja formação é compromisso do ensino, em qualquer nível" (PROJETO, 2007, p. 11).

O PPP parece se distanciar das discussōes sobre letramentos (no plural) em LI, visto que trata a escrita e a leitura como duas modalidades separadas e estáticas, o que vai de encontro à perspectiva dos novos letramentos e multiletramentos. Walkyria Monte-Mór (2011) questiona a formação de professores de inglês nos moldes tradicionais a reboque dos cursos de idiomas, com treinamentos, miniaulas, enfoque nas quatro habilidades, etc. Esse modelo não somente não dá conta da diversidade de contextos encontrados na escola básica regular, como também deixa de levar em consideração as discussões relativas às tecnologias de comunicação em suas várias manifestações e suportes nas mãos dos alunos. O modelo de ensino de LI nos moldes dos novos letramentos implica produção de sentido pelo deslocamento da centralidade da escrita, significando que um texto pode ter imagens; pode estar ligado a outros textos pelo hipertexto; pode permitir a inserção de sons, vídeos ou músicas; pode oferecer a possibilidade de opinar sobre o evento. De acordo com a autora, ao falar sobre a importância da imagem na construção de sentidos pela intencionalidade do locutor,

na esteira dessa linguagem visual, emergem ou sobressaem-se outras modalidades de comunicação: músicas acompanham mensagens virtuais; veem-se e leem-se corpus em movimento, como nas mensagens postadas no YouTube [...]. Observa-se que essas não são apenas formas de comunicação, mas também de expressão, interação, nas quais há agência dos interlocutores (MONTE-MÓR 2011, p. 13).

Disso resulta que escrita e leitura não podem ser nem dicotomizadas nem distanciadas dos contextos por onde circulam, mas devem integrar um conjunto de possibilidades de comunicação, juntamente com outras manifestaçôes de produção de sentidos. O conceito de letramentos, no plural, deve dar conta dessas possibilidades de produção de sentido e construção de conhecimento, o que claramente não acontece no PPP em vigor. 


\section{A questão da tecnologia}

Em vários momentos, o PPP menciona o uso de tecnologias tanto para a formação do docente quanto na instrumentalização do professor para a atuação na sala de aula de língua inglesa. Em primeiro lugar, observa-se que a tecnologia é listada como último item relacionado ao perfil do egresso, colocando tecnologia e conceitos científicos em uma relação de coordenação. Isto é, o projeto posiciona tecnologia e conceitos científicos sintaticamente em equivalência, dizendo que espera do egresso da "assimilação crítica de novas tecnologias e conceitos científicos". Segundo Pennycook (2001), o sentido do termo crítico pode variar de acordo com a orientação teórico-ética a que está filiado. A "assimilação crítica" pode significar um ponto de vista engajado em problemas sociais, culturais e políticos, incluindo questões relativas à inclusão, ao poder, às disparidades sociais, às diferenças e resistências. Isto é, o termo crítico pode se relacionar a um posicionamento político, entendendo a realidade como inacabada e possível de ser alterada por uma ação de cunho intervencionista, portanto política.

Por outro lado, o termo pode também se referir a um posicionamento mais neutro em relação às mesmas questôes, o que implica um afastamento da realidade concreta com o objetivo da observação e apontamento dos problemas percebidos, mas não uma ação modificadora, interventora. Parecenos que "assimilação crítica" se aproxima desse segundo sentido, porque assimilação pode ser entendida como aprendizado, assim como assimilamos conceitos científicos; contudo, não quer dizer fazer uso das tecnologias. Em outras palavras, o trecho espera que o aluno egresso possa assimilar a tecnologia e os conceitos científicos, mas deixa a utilização desses dois a critério do professor. Essa percepção sobre o sentido de assimilação se confirma algumas linhas à frente do perfil do egresso, quando lemos que

o formando deve aprender a compreender os fenômenos e não a memorizar elementos cujo alcance e significado desconhece dentro do domínio do conhecimento linguístico. Não se está negando a importância das informações, mas se está mostrando que sua aquisição deve estar direcionada para a compreensão (PROJETO, 2007, p. 15).

A tecnologia, coordenada sintaticamente com os conceitos científicos, parece ser vista de forma abstrata e distante do cotidiano do ensino e aprendizagem de línguas. Termos como fenômenos e compreensäo constroem um campo semântico particular para o entendimento do sentido de tecnologia, 
porque outros termos, como utilização ou apropriaçãa, que corresponderiam a uma posição mais objetiva de qualificação do egresso, somente aparecem mais à frente, distanciados do perfil e relacionados às habilidades. Parece-nos que a tecnologia é um fenômeno da mesma composição que um fenômeno científico, devendo ser estudada e, posteriormente, compreendida. Ao mesmo tempo, ela parece ser vista como objeto de facilitação para o contínuo aprendizado do professor. Nas palavras do PPP, "a renovação tecnológica acelerada e a velocidade de produção e circulação de informações levam a pensar que, no momento, a educação deve produzir no aluno uma capacidade de continuar aprendendo" (p. 15).

A questão tecnológica como fenômeno a ser estudado desemboca nas habilidades esperadas para a construção do saber do professor de LI de forma determinista. Em outras palavras, parece-nos que há uma relação mecânica entre estudar o fenômeno, compreendê-lo e, posteriormente, aplicá-lo. Essa relação aparece claramente nas habilidades a serem desenvolvidas nos graduandos durante o curso: "utilização de recursos de informática necessários ao exercício da profissão" (PROJETO, 2007, p. 16). Isto é, a tecnologia, travestida de recursos de informática, em constante evolução, deve ser estudada e compreendida para que possa ser utilizada no exercício da atividade docente.

Apesar da tentativa da inclusão do ponto de vista tecnológico, o PPP parece se distanciar consideravelmente das discussões sobre comunicação e tecnologia no sentido de que a tecnologia, em suas várias manifestações, é constitutiva da realidade não somente dos graduandos de Letras, futuros professores de inglês, como também dos alunos desses professores. De acordo com Carmen Luke (2000), as tecnologias sempre estiveram presentes no nosso cotidiano, o que não significa que funcionem igualmente para todas as pessoas em todas as camadas da sociedade, cujos efeitos são mediados pelos usos dados a essas tecnologias e pelos contextos de uso. Desse modo, tratar de tecnologias em sala de aula e, mais especificamente, de informática, é pensar em questōes relativas à sua função social dentro do contexto de atuação do professor; à condição de participação nas atividades humanas das tecnologias, ou seja, na promoção das atividades em sociedade que a tecnologia permite; e, por fim, à produção de conhecimento que a tecnologia proporciona. A autora afirma que as novas tecnologias se incluem nesse contexto de construção de conhecimento pela percepção das redes de conhecimento possibilitadas. Nas palavras da autora, 
há muitas redes sociais e níveis de conhecimento em que a tecnologia se insere. Uma vez compreendidas as relações sociais em que se inserem as tecnologias, começamos a perceber a futilidade dos argumentos tecnológicos deterministas ${ }^{8}$ (LUKE 2000, p. 74, tradução nossa).

Essa perspectiva mais ampla e integradora, com a qual concordamos, não está presente no PPP. Também sentimos falta da integração entre tecnologia e letramentos, o que nos pareceu serem duas instâncias diferenciadas e distantes. Desse modo, é nossa convicção que o PPP necessita de uma revisão de conceitos e perspectivas para se adequar à evolução da sociedade.

\section{Considerações finais}

Nosso caminho partiu da discussão sobre a relevância de um PPP como ponto organizador e centralizador das ações e intervenções políticas por meio das práticas pedagógicas constituídas. Colocamos a importância da constante de revisão desse documento, com o objetivo de transformá-lo em instrumento sempre atualizado, evoluindo enquanto documento fluido como deve ser.

Estabelecemos, então, alguns parâmetros que consideramos relevantes para o entendimento do que queremos dizer com letramentos (no plural) dentro do contexto de formação dos professores no estado de Alagoas. Dissemos que os letramentos devem estar presentes no PPP em duas formas. Em primeiro lugar, devem fazer parte do conteúdo didático-pedagógico desses futuros professores para utilização nas salas de aula. Em segundo lugar, os letramentos devem também estar presentes no próprio conteúdo linguísticodiscursivo formativo desses graduandos que precisam aprender a LI ao mesmo tempo que se instrumentalizam teórica e praticamente.

Em seguida, demonstramos que o PPP trata de letramento (no singular), trazendo a escrita e a leitura para a centralidade dos processos de ensino e de aprendizagem da LI. A centralidade apenas nessas duas modalidades deixa de lado outras possibilidades de interação e de produção de sentidos advindas, por exemplo, das relações estabelecidas entre imagem, som, letra e suporte, tão relevantes nos dias de hoje.

\footnotetext{
8 " [...] there are many social networks and levels of knowledge in which technologies are embedded. Once we unravel the social relations in which technologies are embedded, we can begin to see futility of any technological determinist arguments.
} 
Por fim, na interação entre letramentos e tecnologia, observamos que o PPP é bastante cauteloso a esse respeito, estabelecendo um distanciamento científico, quando se propóe a tratar a tecnologia como um fenômeno a ser estudado, desvendado. Por outro lado, o PPP falha quando desconsidera a possibilidade da utilização da tecnologia como ferramenta concreta de comunicação e de produção de conhecimentos pela facilitação do contato, que é um ponto crucial no favorecimento da circulação de valores entre culturas.

Percebemos, assim, que o PPP tem a urgente necessidade de revisão de seus conceitos e pontos de vista sobre os letramentos, incluindo-se também as relações com a tecnologia. $\mathrm{O}$ desafio proposto pelos letramentos na formação de professores se encontra, antes mesmo de sua colocação em prática, na própria constituição do PPP.

\section{Referências}

AMORIM, M. O pesquisador e seu outro: Bakhtin nas ciências humanas. São Paulo: Musa, 2003.

BAKHTIN, M. Estética da criação verbal. Tradução de Paulo Bezerra. 4. ed. São Paulo: Martins Fontes, 2003.

BAKHTIN, M.; VOLOCHINOV, V. N. Marxismo e filosofia da linguagem. Tradução de Michel Lahud e Yara Frateschi Vieira. 14. ed. São Paulo: Hucitec, 2010.

CHARTIER, R. A ordem dos livros: leitores, autores e bibliotecas na Europa entre os séculos XIV e XVIII. Tradução de Mary del Priori. Brasília: Editora UnB, 1999. (Coleção Tempos).

FREIRE, P. Política e educação: ensaios. 5. ed. São Paulo: Cortez, 2001. (Coleção Questôes de Nossa Época; 23).

LANKSHEAR, C.; KNOBEL, M. New literacies: everyday practices and social learning. Berkshire; New York: McGraw Hill; Open University Press, 2011.

LO BIANCO, J. Multiliteracies and multilingualism. In: COPE, B.; KALANTZIS, M. (Ed.). Literacy learning and the design of social futures. London: Routledge, 2000. p. 89-102.

LUKE, C. Cyber schooling and technological changes: multiliteracies for new times. In: COPE, B.; KALANTZIS, M. (Ed.). Literacy learning and the design of social futures. London: Routledge, 2000. p. 79.

MONTE-MÓR, W. Prefácio. In: JORDÃO, C. et al. Por uma fomação "desformatada": práticas com professores de língua inglesa. Campinas: Pontes, 2011. p 11-26. 
MORIN, E. Saberes locais e saberes globais. Rio de Janeiro: Garamond, 2000. PENNYCOOK, A. A linguística aplicada nos anos 90: em defesa de uma abordagem crítica. In: SIGNORINI, I.; CAVALCANTI, M. (Org.). Linguistica aplicada e trasnsdisciplinaridade. Campinas: Mercado de Letras, 1998. p. 23-49. PENNYCOOK, A. Critical applied linguistics: a critical introduction. New Jersey; London: LEA, 2001.

PROJETO pedagógico do curso de Letras Licenciatura em Inglês. Universidade Federal de Alagoas, Faculdade de Letras, Maceió, 2007. Mimeografado.

TARONE, E.; ALLWRIGHT, D. Second language teacher learning and second language student learning: shaping the knowledge base. In: TEDICK, D. Second language teacher education: international perspectives. New Jersey: LEA, 2005. p. 5-24.

THE NEW LONDON GROUP. A pedagogy of multiliteracies: designing social futures. In: COPE, B.; KALANTZIS, M. (Ed.). Literacy learning and the design of social futures. London: Routledge, 2000. p. 9-36.

TODOROV, T. A conquista da América: a questão do outro. São Paulo: Martins Fontes, 2003.

Recebido em 27/02/2012. Aprovado em 10/09/2012. 